\section{Does caffeine consumption during pregnancy increase the risk of fetal mortality? A literature review}

\author{
O consumo de cafeína durante a gestação \\ aumenta o risco de mortalidade fetal? \\ Uma revisão da literatura
}

Alicia Matijasevich 1

Iná S. Santos 1

Fernando C. Barros ${ }^{2}$

\begin{abstract}
${ }^{1}$ Faculdade de Medicina, Universidade Federal de Pelotas, Pelotas, Brasil.

2 Centro Latinoamericano de Perinatología

y Desarrollo Humano, Organización Panamericana de la Salud/Organización Mundial de la Salud, Montevideo, Uruguay.

Correspondence A. Matijasevich

Programa de Pós-graduação em Epidemiologia, Departamento de Medicina Social, Faculdade de Medicina, Universidade Federal de Pelotas. Av. Duque de Caxias 250, Pelotas, RS 96030-002, Brasil. amatija@yahoo.com
\end{abstract}

\begin{abstract}
The aim of this study was to evaluate the available epidemiological evidence of the effect of caffeine consumption during pregnancy on fetal mortality. A systematic qualitative review of observational studies that referred to any source of exposure to caffeine from food in pregnancy and to fetal mortality as the outcome was conducted in the databases MEDLINE and LILACS. Studies published between January 1966 and September 2004 were searched. The following descriptors were used: "caffeine", "coffee", "tea", "cola", and "cacao" to define the exposure and "fetal death", "stillbirth", "fetal demise", and "fetal loss" to define the outcome. The search strategy retrieved 32 publications, but only six met the inclusion criteria and three were included. One more article was found using "see related articles" feature in PubMed. A total of four publications were included in the review. The small number of publications addressing this subject, methodological limitations, inaccurate exposure assessment in all the studies, overall risks only marginally significant in most cases, and the possibility of publication bias preclude stating with certainty that caffeine consumption is actually associated with fetal death.
\end{abstract}

Caffeine; Fetal Death; Pregnancy

\section{Introduction}

Caffeine (1,3,7-trimetylxanthine) is a plant alkaloid, structurally related to DNA purine bases. It is probably the most frequently ingested pharmacologically active substance in the world. The most commonly known sources of caffeine are coffee, cocoa beans, cola nuts, and tea leaves. Caffeine constitutes a substantial portion of many over-the-counter medications, such as cold tablets, allergy or analgesic preparation, appetite suppressants, diuretics, and stimulants 1 . At doses relevant to general human consumption, caffeine exerts most of its pharmacological effects by acting as an antagonist of adenosine receptors 2 .

Following studies in animals, caffeine intake during pregnancy has been suggested as a risk factor for adverse reproductive outcomes. This hypothesis is biologically plausible based on the fact that caffeine ingested by the mother is rapidly absorbed from the gastrointestinal tract into the bloodstream, readily crosses the placenta, and is distributed to all fetal tissues, including the central nervous system. Potential effects of caffeine on fetal development may follow prolonged accumulation of caffeine in pregnant women (metabolic half life increases steadily from 4 hours during the first trimester to 18 hours during the third trimester) and passage to the fetus which lacks the necessary enzymes to metabolize it 3,4 . 
Although much epidemiological work has been conducted, results from studies investigating the association between caffeine consumption and outcomes such as decreased fetal growth, preterm delivery, and spontaneous abortion have been conflicting and the available information is incomplete and remains controversial 5,6,7,8,9. Regarding fetal mortality, studies in monkeys after chronic caffeine exposure showed that those treated with caffeine in their drinking water had an increased rate of stillbirths. Although the experiment attempted to mimic human caffeine consumption, it is difficult to extrapolate these results to human beings due to differences in the caffeine dose and exposure regimen as well as metabolic and physiological differences between species 10. In humans, although epidemiological studies examining the relationship between caffeine consumption and fetal mortality have been published since 1977 11, the available information is still scarce and the overall evidence for such a relationship remains uncertain. With the aim of evaluating the available epidemiological evidence of the effect of caffeine consumption during pregnancy on fetal mortality, a systematic qualitative review was conducted.

\section{Methodology}

We reviewed observational studies that referred to any source of exposure to caffeine from food in pregnancy and to fetal mortality as the outcome (deaths occurring at twenty or more complete weeks of gestation).

Strategies to identify studies included an electronic search of the MEDLINE and LILACS bibliographic databases and other specialized libraries (Medcarib, Repidisca, Adolec), consultation with experts, and use of the "see related articles" feature in PubMed for articles meeting our eligibility criteria. The MEDLINE search strategy used as keywords "caffeine", "coffee", "tea", "cola", and "cacao" to define the relevant exposure and "fetal death", "stillbirth", "fetal demise", and "fetal loss" to define the outcome. The search strategy was limited to articles dealing with human subjects, published between January 1966 and September 2004, with no language restriction. To ensure completeness, the reference lists of all identified studies were reviewed. The search strategy in the LILACS database used the same keywords. Only publications in peer-reviewed journals were considered.
For each article that was included, an overall score of the methodological quality was given according to the checklist proposed by Downs \& Black 12 . This checklist considers aspects related to reporting, external and internal validity, bias, confounding, and power of the study to detect clinically important effects. The quality score was adapted for observational studies; items that did not apply were excluded, and we were able to retain 26 of the 31 original points.

For each individual report, letters to editors and responses by authors, and previous reviews which included commentaries on the articles were also reviewed. Methodological issues of the included studies were analyzed separately.

\section{Results and discussion}

The search strategy in the MEDLINE database retrieved 32 publications, of which only 6 met the inclusion criteria. The remaining publications were excluded for the following reasons: eight studied outcomes other than fetal death (abortion, preterm, low birth weight, congenital disorders, or intrauterine growth retardation); one was a case report; seven were letters to editors; six were reviews; one was not related to caffeine consumption during pregnancy; and three were not related to caffeine consumption at all.

Among the six articles which met the inclusion criteria, three were included 11,13,14. Among the excluded articles, two focused their exposures on alcohol and cigarette smoking 15,16 and used the same database as in one of the included articles 13 and the other presented data already reported elsewhere 17. The "see related articles" feature in PubMed allowed us to find one more article 18. Hand-searching the references of the articles which fulfilled the eligibility criteria, no other publication was found. The search strategy in the LILACS database and in the other specialized libraries did not locate articles related to caffeine consumption and fetal mortality.

Table 1 presents a summary of the four studies displayed in chronological publication order. The first study was published in 1977 and the most recent in 2003. Two studies were from the United States, one from Denmark, and the other from Canada. In relation to the design, two were case-control studies, one was a cohort study, and the other a cross-sectional 
Summary of the identified studies.

\begin{tabular}{|c|c|c|c|c|c|c|}
\hline $\begin{array}{l}\text { Investigator; } \\
\text { study design }\end{array}$ & $\begin{array}{l}\text { Location and } \\
\text { study population }\end{array}$ & $\begin{array}{l}\text { Caffeine exposure: } \\
\text { source of information } \\
\text { and measurement }\end{array}$ & Outcome & $\begin{array}{l}\text { Control for } \\
\text { confounding }\end{array}$ & Results & Score* \\
\hline $\begin{array}{l}\text { Weathersbee et al. }{ }^{11} \text {; } \\
\text { cross-sectional }\end{array}$ & $\begin{array}{l}\text { USA: } 800 \\
\text { households; } \\
\text { non-response } \\
\text { rate } 38.9 \%\end{array}$ & $\begin{array}{l}\text { Mail questionnaire } \\
\text { after delivery; } \\
\text { mg/day of caffeine }\end{array}$ & $\begin{array}{l}\text { Stillbirth, } \\
\text { spontaneous } \\
\text { abortion, } \\
\text { premature birth }\end{array}$ & no & $\begin{array}{l}5 \text { stillbirths }(31.3 \%) \\
\text { in } 16 \text { households } \\
\text { where woman } \\
\text { consumed } \geq 600 \mathrm{mg} / \\
\text { day; } 38 \text { stillbirths } \\
(10.7 \%) \text { in } 356 \\
\text { households where } \\
\text { neither the woman } \\
\text { nor the man } \\
\text { consumed caffeine }\end{array}$ & 4 \\
\hline $\begin{array}{l}\text { Little \& Weinberg } 18 \\
\text { case-control }\end{array}$ & $\begin{array}{l}\text { USA: cases - women } \\
\text { with stillbirth }(n= \\
1,835) \text {; controls - } \\
\text { women with live } \\
\text { births ( } n=2,832) ; \\
\text { non-response rate: } \\
34.3 \% \text { of cases } 25.8 \% \\
\text { of controls }\end{array}$ & $\begin{array}{l}\text { Mail questionnaire } \\
\text { after delivery; } \\
\text { number of cups of } \\
\text { caffeinated coffee } \\
\text { and/or tea per day }\end{array}$ & Stillbirth & $\begin{array}{l}\text { Adjustment for: } \\
\text { smoking and alcohol } \\
\text { intake, region of } \\
\text { birth, maternal age, } \\
\text { race, BMI, parity, } \\
\text { and education }\end{array}$ & $\begin{array}{l}\text { For total deaths: } \geq 5 \\
\text { cups of coffee/tea } \\
\text { per day; ORa }=1.37 \\
(95 \% \mathrm{Cl}: 1.03-1.82)\end{array}$ & 19 \\
\hline $\begin{array}{l}\text { Infante-Rivard et al. 14; } \\
\text { case-control }\end{array}$ & $\begin{array}{l}\text { Canada: cases - } \\
\text { women with fetal } \\
\text { loss; controls - } \\
\text { women without fetal } \\
\text { loss matched for } \\
\text { period of pregnancy; } \\
\text { rate of refusal: } 30.0 \% \\
\text { of cases } 1.5 \% \text { of } \\
\text { controls }\end{array}$ & $\begin{array}{l}\text { Questionnaire at } \\
\text { the time of } \\
\text { ascertainment; } \\
\text { mg/day of caffeine }\end{array}$ & Fetal loss & $\begin{array}{l}\text { Adjustment for: } \\
\text { smoking and alcohol } \\
\text { intake, maternal } \\
\text { age, education, } \\
\text { work schedule, } \\
\text { and uterine } \\
\text { abnormality }\end{array}$ & $\begin{array}{l}163-321 \mathrm{mg} \text { of } \\
\text { caffeine/day, } \\
\text { ORa }=1.95(95 \% \mathrm{Cl} \text { : } \\
1.29-2.93) ; \\
>321 \mathrm{mg} / \text { day, } \\
\text { ORa }=2.62 \\
(95 \% \mathrm{Cl}: 1.38-5.01)\end{array}$ & 19 \\
\hline $\begin{array}{l}\text { Wisborg et al. 13; } \\
\text { cohort }\end{array}$ & $\begin{array}{l}\text { Denmark: } 18,478 \\
\text { singleton } \\
\text { pregnancies } \\
\text { delivery after } 28 \\
\text { weeks of gestation }\end{array}$ & $\begin{array}{l}\text { Questionnaire at } \\
\text { about } 16 \text { weeks of } \\
\text { gestation; number of } \\
\text { daily cups of coffee }\end{array}$ & Stillbirth & $\begin{array}{l}\text { Adjustment for: } \\
\text { smoking and alcohol } \\
\text { intake, parity, } \\
\text { maternal age, } \\
\text { education, } \\
\text { employment status, } \\
\text { BMI }\end{array}$ & $\begin{array}{l}\geq 8 \text { cups of coffee/ } \\
\text { day, ORa = 3.0 } \\
\text { (95\% } \mathrm{Cl}: 1.5-5.9) ; \\
\mathrm{ORa}=2.2(95 \% \mathrm{Cl} \text { : } \\
1.0-4.6)- \text { adjusted } \\
\text { for smoking -; } \\
\text { ORa=2.6 }(95 \% \mathrm{Cl} \text { : } \\
1.3-5.3)- \text { adjusted } \\
\text { for alcohol intake -; } \\
\text { ORa }=2.2 \text { ( } 95 \% \mathrm{Cl}: \\
\text { 1.0-4.7) - adjusted } \\
\text { for all confounders }\end{array}$ & 20 \\
\hline
\end{tabular}

$\mathrm{OR}_{\mathrm{a}}=$ adjusted odds ratio; $\mathrm{BMI}=$ body mass index.

* Downs \& Black score.

study. As for outcomes, two investigated fetal deaths with 28 complete weeks of gestational age or more, one included abortions and fetal deaths, and the other studied fetal deaths but did not define this term.

Quality ratings 12 showed that one of the studies had a very low qualification rate, reflecting poor quality and weaknesses in the study design 11 . According to the criteria proposed by Downs \& Black 12, this study failed to define the main outcomes, exposures, and principal confounders and did not describe the study population's characteristics or the missing cases. External and internal validity was doubtful, and the study power was not mentioned. The main limitations of the three other studies were: not providing $\mathrm{p}$-values for the principal outcomes 13,18 , not presenting the distribution of the main confounding factors in either the study sample or the source population 14,18, and not describing the study's power to detect significant results 13,14,18. Discussion on study design, analysis issues, and results of the studies are summarized subsequently. 
Weathersbee et al. 11 pioneered the evaluation of the relationship between coffee consumption and fetal mortality. However, serious methodological flaws disallow considering their results as scientifically valid. The authors conducted a retrospective survey of women living in 800 households chosen by random sampling of medical records from former obstetric patients at the University of Utah Medical Center or at one of the six Intermountain Health Care Hospitals in Utah and Southern Idaho, in 1974 or 1975. A 52-item questionnaire was mailed to each household to obtain information on levels of beverage consumption by family members. Caffeine intake from coffee, tea, and cola was calculated using conversion factors presented by the authors, and the pregnancy outcomes were spontaneous abortion, stillbirth, and preterm birth.

The paper is far from clear, and the lack of information may have contributed to the difficulty previous reviewers also faced in correctly identifying the study design. Heller 19 called it a retrospective cohort study, but because the subjects were not followed in a forward direction from exposure to outcome and the exposure and outcome were both determined at the same point in time, this design fits in the group of cross-sectional studies 20.

Other problems of the paper were: no definition of the "random sampling" process and no description of the inclusion and exclusion criteria. In addition, the proportion of non-respondents was high (around 39.0\%), affecting the sample's representativeness. Moreover, the investigators did not report any comparison between respondents and non-respondents 9 .

Concerning caffeine consumption, it was not clear whether the question was asked specifically in relation to the index pregnancy, and as information was collected after the birth outcome, recall bias may also have affected the reported consumption patterns 9 . When referring to categories of caffeine consumption, the authors found that 5 out of 16 pregnant women who consumed $\geq 600 \mathrm{mg} /$ day of caffeine had stillbirths $(31.3 \%)$, whereas the incidence of stillbirths among 356 women who did not consume caffeine was $10.7 \%$. However, since they mixed men's and women's caffeine consumption, the results are very hard to interpret.

Finally, the authors failed to adjust for possible confounders like cigarette smoking or alcohol consumption, based on the belief that since the study population belonged to a preponderantly Mormon community, they would not be affected by such exposures. Their line of reasoning was that per capita cigarette and al- cohol sales in Utah were considerably lower than in the rest of the United States. This ecological argument does not permit to infer what occurs at the individual level 20 , and thus no valid conclusions can be drawn from their results.

In 1993, Little \& Weinberg 18 published a case-control study on risk factors for antepartum and intrapartum fetal mortality. Data were obtained from the 1980 National Natality Survey and the National Fetal Mortality Survey conducted by the National Center for Health Statistics in the United States. Multiple births and births to mothers with serious medical problems and to unmarried mothers were excluded. After a complex process of sampling 1,835 cases (women with fetal deaths with at least 28 weeks of gestation or $\geq 1,000 \mathrm{~g}$ if gestational age was unknown) and 2,832 controls were included. A questionnaire was mailed after delivery to both groups requesting information on maternal demographics, reproductive history, smoking, drinking, caffeinated coffee and/or tea use, and other variables. The information was completed with data from hospital records and birth/death certificates.

The non-response rate was higher among cases $(34.3 \%)$ than controls $(25.8 \%)(\mathrm{p}<0.001)$ and no attempt was made to describe characteristics of responders and non-responders. It is possible that sample distortion bias could have affected the study 21.

The results did not provide information about missing values for study variables. Although it is stated that the analysis was restricted to cases and controls which had valid values on all variables, the total number of cases and controls vary from table to table. In the descriptive analysis 2,565 controls were included and in the different tables showing the results of the adjusted analyses there were 2,668, 2,619 , and 1,565 live births, respectively. The authors did not mention having calculated sample sizes, and in the separate analysis of antepartum and intrapartum fetal deaths there is no information regarding the study's power to detect differences between groups.

Besides the fact that the study was not primarily designed to analyze the relationship between caffeine consumption during pregnancy and fetal mortality, the measurement of caffeine intake ("cups of coffee/tea with caffeine per day during pregnancy") is far from adequate. In addition, no information was provided about how caffeine intake was ascertained, nor whether the authors considered mean coffee/tea consumption throughout pregnancy or during a specific gestational period. 
The crude results showed that $20.4 \%$ of mothers of live born infants, $23.4 \%$ of those with antepartum deaths, and $19.5 \%$ of those with intrapartum deaths consumed $\geq 3$ cups of caffeinated coffee and/or tea daily during pregnancy. In the adjusted analysis, the highest consumption category was changed to $\geq 5$ cups of coffee/tea per day, and eight probable confounders (region of birth, mother's age, race, pre-pregnancy body mass index, parity, education, and cigarette and alcohol consumption) were analyzed. The highest category of caffeine consumption showed a marginally significant increase in the risk of total fetal mortality (OR = 1.37; 95\%CI: 1.03-1.82), but not for antepartum or intrapartum deaths. No significance levels are provided, and in view of the marginal significance in the highest consumption category, one cannot conclude that caffeine consumption is a risk factor for fetal mortality.

Little \& Weinberg 18 pioneered the separate analysis of risk factors for fetal death according to time of death (antepartum or intrapartum), which is an important contribution by the authors. It apparently makes more sense to study caffeine consumption in relation to prenatal fetal mortality, since the determinants of intrapartum deaths are much more closely related to access to quality of medical care during labor and delivery than to maternal factors 22 .

Infante-Rivard et al. 14 conducted a matched case-control study planned primarily to examine the association between lupus anticoagulants, anticardiolipin antibodies, and fetal loss. Data on caffeine intake were also collected, and the association between caffeine intake before and during pregnancy and increased risk of fetal loss was investigated. Cases were women hospitalized with a medically confirmed diagnosis of spontaneous abortion or fetal death from May 1987 to November 1989 at Hospital Sainte-Justine in Montreal, Quebec. Three controls were matched to each case in the following periods of gestation: $\leq 16,17-20$, 21-27, and $\geq 28$ weeks. Controls were women in the same period of pregnancy as cases and who had not experienced a fetal loss. They were recruited from pregnant women expected to deliver at the hospital when they presented for routine blood analysis. Previous history of spontaneous abortion was an exclusion criterion for both cases and controls. A total of 331 cases and 993 controls were studied.

The authors excluded patients admitted at night and discharged before the next morning, as well as those admitted on weekends or legal holidays, a methodological issue that generated criticism 9,21,23. However, the fact that cases were not representative of all cases in the target population would not necessarily lead to bias in the estimate of caffeine consumption/ fetal loss association. On the other hand, the high percentage of refusals among cases $(30.0 \%)$ and the impossibility of determining whether cases who agreed to participate in the study were more or less likely to have a history of caffeine consumption (as compared to those in the target population) may could have produced a bias. In addition, controls were recruited among women attending prenatal care while cases were recruited upon their hospitalization and no information was provided as to whether cases had been receiving prenatal care. Moreover, prenatal care was not included among the potential confounders presented by the authors. This imposed selection criterion only for controls may be another source of selection bias in this study 9,23.

Another debatable methodological aspect of the study was that the authors mixed abortions and third-trimester fetal deaths $(10.0 \%$ of cases). As already pointed out by Levinton \& Cowan 9 these two different outcomes may have different risk profiles, and caffeine exposure may not affect them in the same way.

An interview covered mother's age, race, education, obstetric history, smoking and alcohol use during pregnancy, occupational exposures, and medical conditions. Regarding caffeine consumption, women were asked about the intake of beverages containing caffeine such as coffee, tea, and cola before pregnancy (the month preceding conception) and during pregnancy (up to the time of study enrollment). Although cases and controls reported their caffeine intake during a relatively comparable reference period, since the investigators obtained information on both current and past caffeine intake, differential recall bias may have affected the study if cases were more likely to remember the exposure than controls. In addition, since the control group was selected among women attending prenatal care, where counseling about avoiding caffeine consumption may have occurred, the control group may have had lower caffeine intake which could lead to an overestimated association between caffeine intake and fetal loss in the study 7,21 .

Quartiles for the distribution of caffeine consumption (<48, 48-162, 163-321, and > 321mg/ day) were used as cutoffs for caffeine intake, and the category of $<48 \mathrm{mg} /$ day was chosen as the reference group. The authors did not describe how they measured caffeine from each source. Apparently, they used a "cup of coffee", a "cup of tea", and a "can of cola" to quantify 
caffeine intake. Several factors affect the amount of caffeine in a given volume of coffee or tea, such as the size of the cup, the brand, and the method of preparation. 1,24,25. Neither a "cup" of coffee nor a "cup" of tea is a precise measure of coffee or tea intake and hence, the dose of caffeine may have been incorrectly calculated, leading to exposure misclassification. Even though this kind of error would be non-differential between cases and controls, differences in measurement methods hinder comparison across studies 7,23 .

After adjusting for maternal age, education, smoking, and alcohol use during pregnancy, uterine abnormalities, and work schedules, caffeine intake during pregnancy was statistically and linearly associated with fetal loss ( $\mathrm{p}<$ 0.001 ). The two highest categories of caffeine intake during pregnancy showed an increased risk of fetal loss (for $163-321 \mathrm{mg} /$ day, $\mathrm{OR}=1.95$; 95\%CI: $1.29-2.93$ and for $>321 \mathrm{mg} /$ day, OR = 2.62; 95\%CI: 1.38-5.01). However, it is not clear what the category of $<48 \mathrm{mg} /$ day means as a reference group.

Choice of controls is a persistently thorny methodological issue in case-control studies 26. According to the investigator's sampling approach for controls, case-control designs can be "traditional", “concurrent", or "inclusive”. In "traditional" designs, controls are sampled from the population still at risk at the end of the study period. In "concurrent" designs, controls can be selected concurrently from those still at risk when a new case is diagnosed and a person originally selected as a control can therefore be classified as a case at a later date. Finally, in "inclusive" designs, controls are chosen from among all individuals in the population regardless of whether they have already had the condition under study. The latter two choices of controls allow to obtain direct estimates of relative risk and relative rate, respectively, instead of OR, an indirect estimate 27. When studying fetal death as outcome, many investigators select live births as controls. They compare their cases with "the best possible controls", those who survived the entire gestational period and were born alive. When the primary objective is to identify an association, then such case-control studies have the greatest power to find a statistically significant result. In the study by Infante-Rivard et al. 14, the fact that controls were recruited at the same time in pregnancy as the cases suggests a "concurrent" design. Controls were women at risk of experiencing a fetal loss because at the time of recruitment their fetuses were alive. As pregnancy advanced, if a woman previously select- ed as a control suffered a fetal loss, ideally she would have had the opportunity to be included as a case as well. In this type of design the control group represents the person-years-at-risk experience, and an analysis matched on time of selection will yield an unbiased estimate of the relative rate (incidence density ratio) instead of OR, which overestimates the real effect 27. Since with such a design the authors found a statistical association between caffeine consumption during pregnancy and fetal death, it would be expected that using a traditional design the magnitude of the observed association would have been even greater.

Wisborg et al. 13 studied the association between coffee consumption during pregnancy and the risk of stillbirth and infant death in the first year of life in a prospective follow-up study. From 1989 to 1996 all pregnant women admitted for delivery at the Aarthus University Hospital in Denmark were invited to participate in the study. The study was restricted to singleton pregnancies among Danish-speaking women who filled in the first questionnaire and delivered after 28 complete weeks of gestation ( $\mathrm{n}=$ 25,395). Further restriction was made to women who had valid information about caffeine intake during pregnancy $(\mathrm{n}=18,478)$. Information about caffeine intake was obtained from a self-administered questionnaire at about 16 weeks of gestation, before the first prenatal visit. The authors restricted the analysis of caffeine to coffee intake measured as number of cups per day ( $0,1-3,4-7$, and $\geq 8$ cups/day).

This was the first study in which the association between coffee intake and fetal death was studied in a cohort design, thus constituting its main strength.

The authors obtained information on current intake of caffeine at about 16 weeks of gestation. Due to the study design and the timing of data collection, this information was not biased by women's knowledge of pregnancy outcome. However, several investigators demonstrated that women can change their pattern of caffeine intake during the course of pregnancy 28. Even though caffeine consumption is more likely to change in the first trimester of gestation, particularly among women suffering morning sickness 29 , since caffeine intake in this study was assessed at only one point in time, it may not precisely reflect the caffeine intake pattern throughout pregnancy. It would have been more appropriate to perform a subsequent assessment of caffeine intake near the end of the pregnancy to decrease the risk that changes in caffeine consumption were not taken into account. 
The authors obtained information about various caffeine sources, but they only analyzed coffee intake because "only few women were exposed to high doses of caffeine from tea and hardly any from drinking chocolate or cola". However, this reason for restricting the analysis to coffee intake is not sound, because to correctly classify the study population in terms of exposure it does not matter whether women reach high caffeine levels from different sources. An extensive accounting of all different sources of caffeine exposure would have allowed the authors to study "caffeine consumption", a more comprehensive exposure.

Concerning coffee quantification, the authors measured coffee intake by "cups" per day, and as we previously mentioned, a cup is not a precise measure of coffee intake. The authors assumed that one cup of coffee contains approximately $100 \mathrm{mg}$ of caffeine, but they did not collect information on beverage cup size, type of coffee, or method of preparation, so the study was subject to exposure misclassification, as already mentioned in the comments on the Infante-Rivard et al. 14 study.

Regarding the results, in the crude analysis maternal consumption of $\geq 8$ cups of coffee/day during pregnancy was associated with increased risk of stillbirth $(\mathrm{OR}=3.0$; $95 \% \mathrm{CI}$ : 1.5 5.9). After adjusting for smoking and alcohol intake during pregnancy, parity, maternal age, marital status, years of education, employment status during pregnancy, and maternal prepregnancy body mass index, the ingestion of 1$3 \mathrm{cups} /$ day $(\mathrm{OR}=0.6 ; 95 \% \mathrm{CI}: 0.3-1.1)$ and $4-7$ cups / day $(\mathrm{OR}=1.4 ; 95 \% \mathrm{CI}: 0.8-2.5)$ were not significantly associated with fetal mortality, but the highest category of coffee consumption was marginally significant $(\mathrm{OR}=2.2 ; 95 \% \mathrm{CI}$ : 1.0-4.7).

Helm 30 criticized the apparent lack of consistency in the category of 1-3 cups of coffee/ day, stating that there is no chance that drinking 1-3 cups/coffee produces a protective effect whereas drinking more coffee leads to a negative effect. However, the association in that category was not significant. Jacobs 31 commented that since the authors do not present the results of an overall test for the entire variable, it was impossible to determine whether, after adjustment, caffeine consumption was still significantly associated with stillbirth.

Cohort studies have several major advantages over other types of observational studies to study the relationship between caffeine intake and fetal death, but very large cohorts are required to ensure adequate numbers of outcome events to yield statistically significant re- sults 26 . In Wisborg et al. 13, the number of fetal deaths in each category of coffee consumption was small, and the risk estimate in women with the highest coffee intake was based on only 11 fetal deaths. Their results, although not definitive, suggest a trend of increasing risk of stillbirths as the number of cups of coffee consumed per day during pregnancy increases.

\section{Conclusions}

The scoring system used to qualify the studies was useful to show that most of the investigations were not highly discrepant in terms of methodological quality. The analysis of the studies revealed that the main methodological flaw was the inaccurate exposure assessment, an issue already pointed out in other reviews focusing on caffeine consumption during human pregnancy.

Despite the biological plausibility that caffeine may increase the risk of fetal death, there is still no clear answer to the question: "Is there a true association between caffeine consumption during pregnancy and the risk of fetal death?". The small number of publications addressing the subject, methodological limitations in the reviewed studies, and overall risks only moderately elevated and marginally significant in most cases disallow stating with certainty that this association actually exists. In addition, due to the absence of studies showing negative results, the possibility of publication bias exists.

As mentioned by Signorello \& McLaughlin 7 in their recent review of the effect of caffeine on abortion, an "optimal" observational investigation on the association between caffeine consumption and fetal death would also demand a huge cohort of women who agree to complete detailed questionnaires on consumption, to take samples for biochemical analysis of the different sources of caffeine consumed, and to allow drawing of repeated blood and urine samples to obtain accurate exposure information. This type of study would be difficult to plan and carry out, and also excessively expensive.

The present review highlighted the scarcity of publications on the subject and the need for well-designed future research to define the role of caffeine in fetal mortality. A well-designed investigation to contribute with convincing evidence on the association between caffeine consumption during pregnancy and fetal death would require a more in-depth approach to caffeine assessment, attempting to be suffi- 
ciently creative to suitably measure caffeine exposure without overly complicating the investigation.

The FDA has been advising women since 1980 to avoid caffeine or consume it only moderately during pregnancy. Although the available information linking caffeine to fetal death is incomplete, many health professional organizations 32 advise pregnant women to reduce caffeine intake. Although suspicion surpasses evidence at present, such caution appears to be prudent.

\section{Resumo}

O objetivo desse estudo foi avaliar a evidência epidemiológica existente a respeito do efeito do consumo de cafeína durante a gravidez sobre a mortalidade fetal. Foi realizada uma revisão qualitativa sistemática dos estudos observacionais que utilizaram como exposição qualquer fonte alimentar de cafeína durante a gestação e como desfecho, mortalidade fetal. A revisão foi conduzida no MEDLINE e LILACS para estudos publicados entre janeiro de 1966 e setembro de 2004. Foram usados os seguintes descritores: "caffeine", "coffee", "tea", "cola" and "cacao" para definir a exposição $e$ "fetal death", "stillbirth", "fetal demise" $e$ "fetal loss" para definir o desfecho. Foram recuperadas 32 publicações, mas somente seis preencheram os critérios de inclusão e três foram incluídas na revisão. Um artigo mais foi encontrado usando o recurso dos "artigos relacionados" do PubMed. Um total de quatro publicações foram incluídas na revisão. O pequeno número de artigos abordando o tema, as limitações metodológicas, a avaliação inacurada da exposição, os riscos marginalmente significativos na maioria dos casos e a possibilidade de viés de publicação impedem que se afirme que o consumo de cafeína esteja associado a morte fetal.

Cafeína; Mortalidade Fetal; Gravidez

\section{Contributors}

A. Matijasevich performed the relevant article searches, systemized the results, and wrote the draft and final version of the article. I. S. Santos oriented the methodological comments. F. C. Barros and I. S. Santos reviewed the draft and contributed to the review of the final version. 


\section{References}

1. International Agency for Research on Cancer. Coffee, tea, maté, methylxanthines and methylglyoxal. Lyon: International Agency for Research on Cancer; 1991. (Monographs on the Evaluation of Carcinogenic Risks to Humans, v. 51).

2. Nehlig A. Pharmacological properties and neurophysiological effects of caffeine. Pharmacopsychoecologia 2002; 15:35-70.

3. Aldridge A, Aranda JV, Neims AH. Caffeine metabolism in the newborn. Clin Pharmacol Ther 1979; 25:447-53.

4. Aldridge A, Bailey J, Neims AH. The disposition of caffeine during and after pregnancy. Semin Perinatol 1981; 5:310-4.

5. Fernandes O, Sabharwal M, Smiley T, Pastuszak A, Koren G, Einarson T. Moderate to heavy caffeine consumption during pregnancy and relationship to spontaneous abortion and abnormal fetal growth: a meta-analysis. Reprod Toxicol 1998; 12:435-44.

6. Santos IS, Victora CG, Huttly S, Morris S. Caffeine intake and pregnancy outcomes: a meta-analytic review. Cad Saúde Pública 1998; 14:523-30.

7. Signorello LB, McLaughlin JK. Maternal caffeine consumption and spontaneous abortion: a review of the epidemiologic evidence. Epidemiology 2004; 15:229-39.

8. Nawrot P, Jordan S, Eastwood J, Rotstein J, Hugenholtz A, Feeley M. Effects of caffeine on human health. Food Addit Contam 2003; 20:1-30.

9. Leviton A, Cowan L. A review of the literature relating caffeine consumption by women to their risk of reproductive hazards. Food Chem Toxicol 2002; 40:1271-310.

10. Gilbert SG, Rice DC, Reuhl KR, Stavric B. Adverse pregnancy outcome in the monkey (Macaca fascicularis) after chronic caffeine exposure. J Pharmacol Exp Ther 1988; 245:1048-53.

11. Weathersbee PS, Olsen LK, Lodge JR. Caffeine and pregnancy. A retrospective survey. Postgrad Med 1977; 62:64-9.

12. Downs SH, Black N. The feasibility of creating a checklist for the assessment of the methodological quality both of randomized and non-randomized studies of health care interventions. J Epidemiol Community Health 1998; 52:377-84.

13. Wisborg K, Kesmodel U, Bech BH, Hedegaard M, Henriksen TB. Maternal consumption of coffee during pregnancy and stillbirth and infant death in first year of life: prospective study. BMJ 2003; 326:420.

14. Infante-Rivard C, Fernandez A, Gauthier R, David M, Rivard GE. Fetal loss associated with caffeine intake before and during pregnancy. JAMA 1993; 270:2940-3
15. Wisborg K, Kesmodel U, Henriksen TB. Exposure to tobacco smoke in utero and the risk of stillbirth and death in the first year of life. Am J Epidemiol 2001; 154:322-7.

16. Kesmodel U, Wisborg K, Olsen SF, Henriksen TB, Secher NJ. Moderate alcohol intake during pregnancy and the risk of stillbirth and death in the first year of life. Am J Epidemiol 2002; 155:305-12.

17. Wisborg K, Kesmodel U, Bech BH, Hedegaard M, Henriksen TB. Does maternal consumption of coffee during pregnancy increase the risk of stillbirth and infant death? A prospective follow-up study. Ugeskr Laeger 2004; 166:278-81.

18. Little RE, Weinberg CR. Risk factors for antepartum and intrapartum stillbirth. Am J Epidemiol 1993; 137:1177-89.

19. Heller J. What do we know about the risks of caffeine consumption in pregnancy? Br J Addict 1987; 82:885-9.

20. Rothman KJ, Greenland S. Modern epidemiology. 2nd Ed. Philadelphia: Lippincott-Raven; 1998.

21. Golding J. Reproduction and caffeine consumption - a literature review. Early Hum Dev 1995; 43:1-14.

22. Kramer MS, Liu S, Luo Z, Yuan H, Platt RW, Joseph KS. Analysis of perinatal mortality and its components: time for a change? Am J Epidemiol 2002; 156:493-7.

23. Wei M. Fetal loss and caffeine intake. JAMA 1994; 272:27.

24. Bunker ML, McWilliams M. Caffeine content of common beverages. J Am Diet Assoc 1979; 74:2832.

25. Barone JJ, Roberts HR. Caffeine consumption. Food Chem Toxicol 1996; 34:119-29.

26. Kramer MS. Clinical epidemiology and biostatistics: a primer for clinical investigators and decision-makers. Berlin: Springer-Verlag; 1988.

27. Rodrigues L, Kirkwood BR. Case-control designs in the study of common diseases: updates on the demise of the rare disease assumption and the choice of sampling scheme for controls. Int J Epidemiol 1990; 19:205-13.

28. Hook EB. Dietary cravings and aversions during pregnancy. Am J Clin Nutr 1978; 31:1355-62.

29. Stein Z, Susser M. Miscarriage, caffeine and the epiphenomena of pregnancy: the causal model. Epidemiology 1991; 2:163-7.

30. Hem E. For mye kaffe øker risikoen for dødfødsel. Tidsskr Nor Laegeforen 2003; 123:1307.

31. Jacobs A. Consumption of coffee during pregnancy: data do not support claim. BMJ 2003; 326:1268.

32. American Medical Association. Caffeine labeling, a report on the safety of dietary caffeine. JAMA 1984; 252:803-6.

Submitted on 21/Dec/2004

Final version resubmitted on $07 /$ Jun/2005 Approved on 24/Jun/2005 